\title{
Nutritional Status and Associated Factors Among Preschool Children in Bahir Dar City Administration, Northern Ethiopia: A Cross-sectional Study
}

\author{
Badasa Rata Jalata \\ Department of Applied Human Nutrition, Faculty of Chemical and Food Engineering, Bahir Dar Institute of Technology, Bahir Dar, Ethiopia \\ Email address: \\ badasa43@gmail.com \\ To cite this article: \\ Badasa Rata Jalata. Nutritional Status and Associated Factors Among Preschool Children in Bahir Dar City Administration, Northern \\ Ethiopia: A Cross-sectional Study. Journal of Food and Nutrition Sciences. Vol. 8, No. 3, 2020, pp. 43-54. doi: 10.11648/j.jfns.20200803.11
}

Received: February 6, 2020; Accepted: March 9, 2020; Published: June 17, 2020

\begin{abstract}
The issue of child malnutrition is decisive as its characteristics are not restricted to the boundary of childhood but rather persist into adulthood. It is also a sober public health problem in which the recent report in the country showed $25 \%$ of children were underweight, $9 \%$ wasted and $38 \%$ stunted. However, underlying variations of these nutritional indicators and determinant factors among localities are poorly understood. Therefore, the main objective of the study is to assess the prevalence of child malnutrition, their causes, and related factors. A cross-sectional study was conducted in Bahir Dar on a total of 615 preschool-age children from February to May 2018. A multistage systematic sampling method was employed to collect quantitative data using a structured questionnaire and anthropometric measurements. The information was processed using Epi-Info 3.5.4 software and exported to SPSS 20 for analysis. NCHS reference population was used to convert height and weight measurements into Z-scores. Bivariate and multivariate logistic regression analysis techniques were employed to identify associated factors with nutritional status. A P-value of less than 0.05 was considered as statistically significant. The study indicated $7 \%$ of the children were wasted, $30.9 \%$ stunted, and $18.7 \%$ underweight. The bivariate and multivariate logistic regression analysis showed that family income $[\mathrm{AOR}=.233$ at $95 \% \mathrm{CI}(.085-.637)]$, number of under-five children [AOR $=2.618$ at $95 \% \mathrm{CI}(1.751-9.124)]$, source of water $[\mathrm{AOR}=2.852$ at $95 \% \mathrm{CI}$ (1.029-7.901)], paternal education $[\mathrm{AOR}=4.19$ at $95 \% \mathrm{CI}(1.298-13.527)]$, maternal education $[\mathrm{AOR}=2.740$ at $95 \% \mathrm{CI}(1.193-6.294)]$, and family head [AOR $=.421$ at $95 \% \mathrm{CI}(.233-.762)]$, were positively associated with underweight. Chronic nutritional problems (stunting) and underweight were highly prevalent in Bahir Dar compared to the urban areas of neighbouring countries while the acute nutritional problem was at an intermediate level. To intervene in this problem, a community-based nutrition program should be established. Additionally, nutritional education should get a high emphasis to improve the nutritional status of children.
\end{abstract}

Keywords: Nutritional Status, Associated Factors, Cross-sectional, Anthropometry, Bahir Dar

\section{Introduction}

Malnutrition continues to be a key public health threat in developing countries. It is the most imperative risk factor for the causing near to 300.000 deaths per year, directly and indirectly, accounted for more than half of all deaths in children [1].

The level of undernutrition among children remains intolerable throughout the world, with a hefty number of children living in the developing world [2]. In the case of Ethiopia, about four hundred and seventy-two thousand children die each year before their fifth birthdays, and the country ranks sixth out of the world in terms of the total number of children deaths [3].

Malnutrition is a primary cause of childhood mortality and morbidity, as well as a permanent impairment of mental and physical growth of survived children. It is also observed in children as the links between poor diet and disease leads to anthropometric deficits. The level of malnourished children in Ethiopia is above the saying with nearly one in two (44\%) stunted (short for their age), 10\% wasted (thin for their height) and $29 \%$ underweight (below weight for their age) [4]. In addition, the common nutrition problems in the country are protein-energy malnutrition and micronutrient deficiencies 
like Vitamin A and Fe [5].

Protein-energy malnutrition commonly occurs during the transitional phase when children are weaned from liquid to semi-solid or solid foods. The complementary food given to infants by mothers or caretakers are deficient both in macronutrients and micronutrients which escort to PEM and specific micronutrient deficiencies. Therefore, ample nutrition and health care during the first thousand days of infant life are vital to prevent malnutrition and child death [5].

Measurement of nutritional status in the community is valuable to estimate growth patterns, spot signs and symptoms of nutritional disorder [5]. Therefore, adequate nutrition and health care during the first two years of infant life are important to prevent malnutrition and child death (5).

The prevalence of child malnutrition in the Amhara region was severe in which $33.4 \%$ underweight $(9.7 \%$ severely underweight), 9.9\% wasted (3.1\% severely wasted) and $52 \%$ stunted (24.2\% severely stunted) [4]. Similar to this, the study conducted in the same setting at Hidabu Abote district exposed $47.6 \%, 30.9 \%$ and $16.7 \%$ of children were stunted, underweight and wasted respectively [6].

Most of these problems occurred in the community due to lack of awareness about nutrition (how to prepare a balanced diet), especially for children less than five years. Therefore, the purpose of this study is to generate baseline data, assess the magnitude and identify determinants of malnutrition among preschool-age children from Bahir Dar district.

The conceptual framework of factors that affect the nutritional status of preschool children in Bahir Dar city administration, which is adapted from Hein and Hoa (2009) is presented in Figure 1.

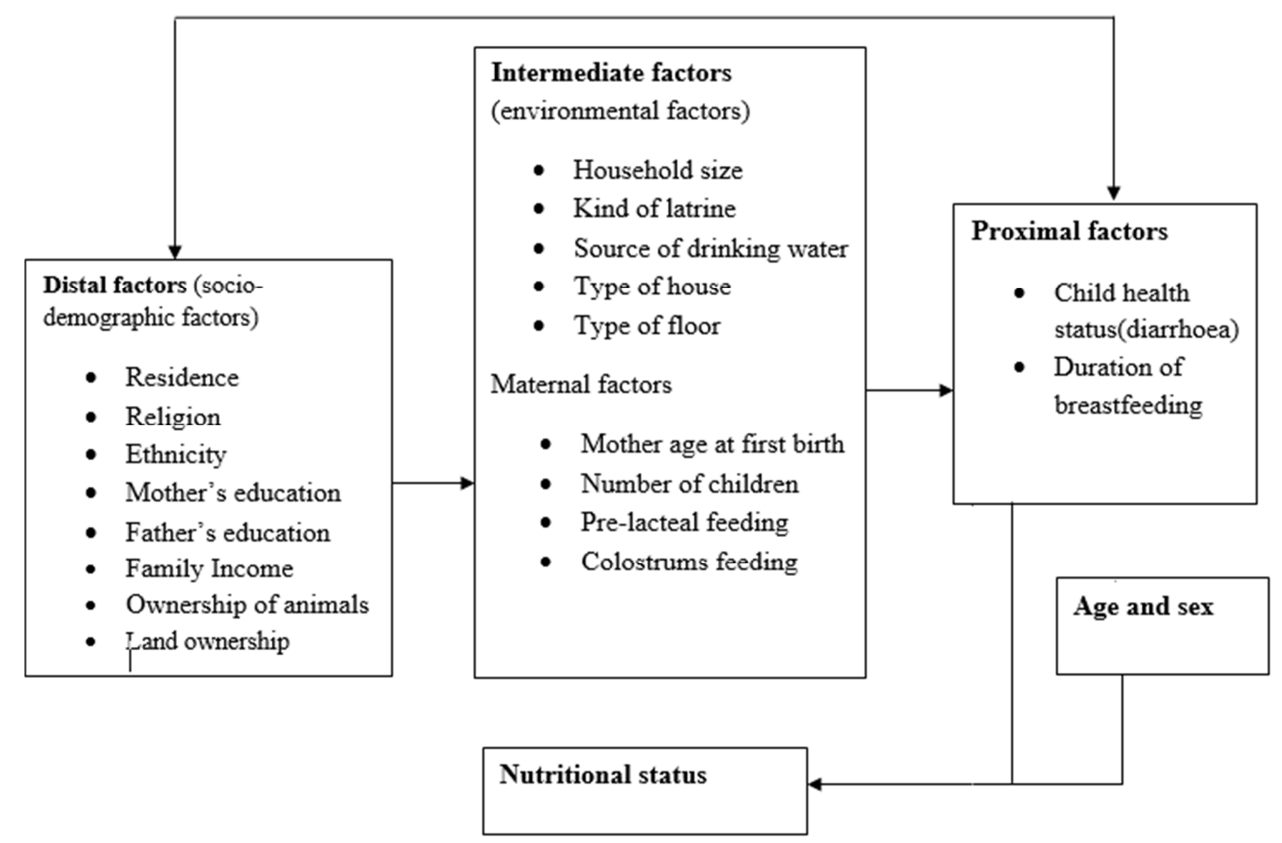

Figure 1. Conceptual framework of factors affects the nutritional status of pre-school age children.

\section{Materials and Methods}

\subsection{Study Design, Setting and Study Population}

A Community based cross-sectional study was conducted to assess the nutritional status and associated factors among preschool children in Bahir Dar city administration from February to May 2018. Bahir Dar is located at 547 kilometres from Addis Ababa (the capital city of the country) to North. The population of the study district was estimated to 291,991 of whom 260,174 were urban inhabitants, while the rest of the population live in rural kebeles. Among this 40,327 were under five years children. All arbitrarily selected preschool children who lived in the area for six months during the study period were taken as the study population.

\subsection{Sample Size Determination and Sampling Technique}

Applying two proportion sample size determination and taking the national prevalence of underweight $26 \%$ for the rural and 13\% for the urban area (mini EDHS 2014) at 95\% confidence interval, the sample size was estimated as;

$$
\frac{\left(z_{1-\alpha / 2} \sqrt{2 \rho(1-\rho)}+z_{1-\beta} \sqrt{\rho_{1}\left(1-\rho_{1}\right)+\rho_{2}\left(1-\rho_{2}\right)}\right)^{2}}{\left(\rho_{2}-\rho_{1}\right)^{2}}
$$

Where, $p=\frac{p 1+p 2}{2}, \mathrm{P}_{1}=0.26, \mathrm{P}_{2}=0.13$ Power of at least $80 \%$, i.e $(1-\beta)=0.80, Z_{1}-\beta=0.84$

$-->(1.962(0.2)(0.8)+0.84(0.26)(0.74)+(0.13)(0.87))$

$2(0.13-0.26)^{2}$

$\mathrm{n}=\mathrm{n}_{1}+\mathrm{n}_{2}=293$ samples

Considering the design effect of two $=293 * 2=586$ and allowance for possible non-response rate of 5\% makes the final sample size; $586+29=615$ HHs. Using proportional allocation based on population density 484 (78.78\%) and 131 $(21.22 \%)$ samples were drawn from urban and rural kebeles respectively.

The study employed a multi-stage sampling scheme using 
stratified, simple random and systematic sampling. The survey was done prior to data collection to identify the total number of kebeles in the district. After that, the study area was stratified into urban and rural kebeles. Considering population size a total of seven kebeles were randomly selected; three from urban and four from rural kebeles. Finally, a systematic random sampling method was applied to select study participants.

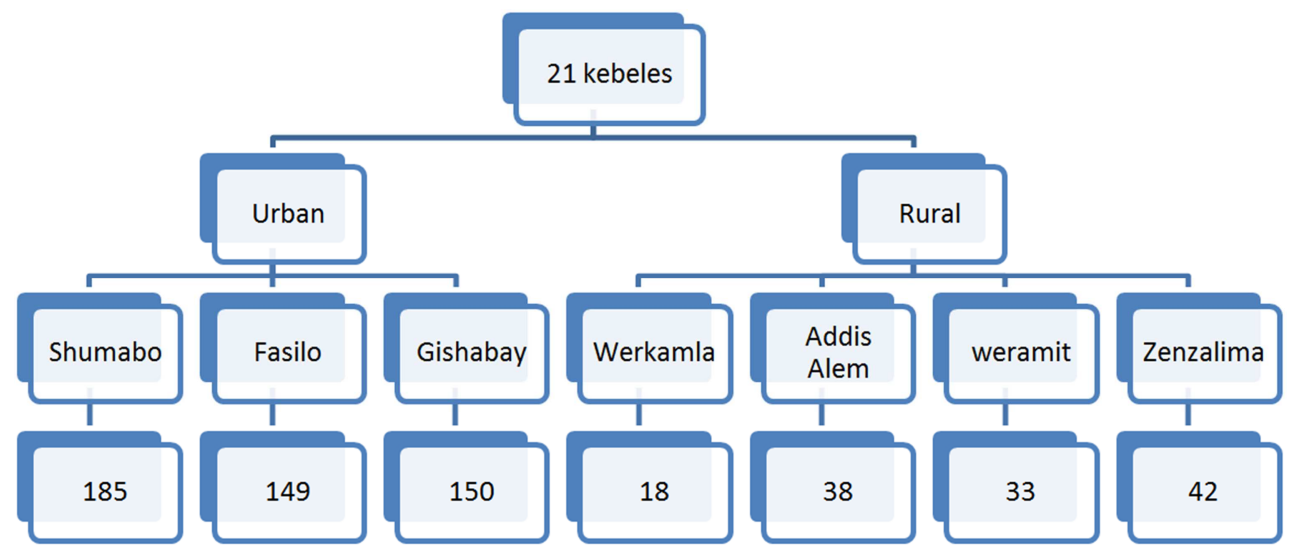

Figure 2. Schematic presentation of the sampling procedure used to select study participants among preschool children in Bahir Dar, Ethiopia, 2018.

\subsection{Variables of the Study}

The dependent variables were nutritional status (stunting, wasting, and underweight) while independent variables were demographic factors, socioeconomic factors, child characteristics, maternal characteristics and environmental conditions.

\subsection{Data Collection Methods}

To collect the data pretested and structured questionnaires was adapted and used from various nutritional status studies. The questionnaire was translated from English to Amharic to collect the data using the interview method. Anthropometric measurements were also taken from study participants. Eight health extension workers were hired to collect data and twodegree holder health professional supervisors were facilitated the data collection process. Weight was measured with the minimum clothing and no shoes using a Salter spring scale and beam balance in kilogram to the nearest of $0.1 \mathrm{~kg}$. Measurement of height was done within a standing position in centimeters to the nearest of $1 \mathrm{~cm}$. MUAC was measured on the left mid-upper arm to the nearest $1 \mathrm{~mm}$ and the result was recorded.

\subsection{Data Quality Control}

To keep the quality of the data the questionnaire has been prepared first in English and then translated to Amharic to make familiar with respondents. The intensive two-day training was given for both data collectors and supervisors by the principal investigator. The prepared questionnaire was pre-tested on $5 \%$ of the sample size in similar kebeles which were not included in the study to see the language clarity, and sequence of the question. The investigator was conducted daily based supervision to explain unclear questions that faced data collectors in a way that did not affect the response. Data were checked daily for completeness, accuracy and consistency both by the supervisor and principal investigator.
Descriptive analyses were carried out to see outliers, missing values and inconsistency that happened both from personal and anthropometric equipment. Weighing scales were regularly calibrated with a known weight object. The scale indicators were checked against zero reading after weighing each child.

\subsection{Data Processing and Analysis}

After the data were checked for completeness and consistency then coded and entered into the computer using the EPI-info 3.5.4 software. The software has a program (Epi-Nut) to convert nutritional data into Z-scores of the indices; Height for Age, Weight for Height and Weight for Age. These indicators were measured taking age and sex into consideration using NCHS reference population. Then, the data was exported to SPSS program for analysis. Descriptive summary using frequencies, proportions, graphs, and crosstabs were used to present the study results. The p-value of less than 0.05 was considered statistically significant. Bivariate and multiple logistic regressions were used to calculate odds ratio with its $95 \%$ confidence interval. It was also used to see the significance of the associated variables and the strength of association between the study variables.

\section{Results}

\subsection{Demographic and Socioeconomic Conditions}

A total of 615 study populations have participated in the study with a response rate of $97.4 \%$. As indicated in Table 1 female-headed households were $13.3 \%$ (urban $15.1 \%$ and rural $6.9 \%$ ) which $86.7 \%$ of respondents were married. Fiftytwo percent of the households had more than four family size and $48 \%$ of them had less than four family members. About $5.9 \%$ of the households had one under five-year children and $18.7 \%$ of the households had two under five-year children and $75.4 \%$ of the households had three under-five children.

Occupations of the head of the households were $24.1 \%$ 
farming, $9.3 \%$ daily labourer, $30.7 \%$ government employee and $17.6 \%$ merchant. About $51.9 \%$ of the mothers had a job which $6.3 \%$ merchant, $11.7 \%$ government employee, $18.7 \%$ private organization and $4.2 \%$ were daily labourer. Majority of the respondents were Amhara (95.7\%) and their religion were; $87 \%$ Orthodox Christian, 9.8\% Muslim, 2.6\% Protestants and $0.7 \%$ others. About $19.2 \%$ of the households earn a monthly income of less than 1500 birr (35.1\% in rural and $14.9 \%$ in urban). About $34 \%$ of fathers decide on the use of money for households in the rural area while $10.7 \%$ in urban area. Farmland ownership was $78.6 \%$ in the rural and $6.0 \%$ in urban area. Animal ownership was $28.6 \%$ (14.7\% in urban and $80.2 \%$ in rural).

Regarding educational status, educational attainment was much higher among urban than rural population. For example, in urban areas, $28 \%$ of females and $15 \%$ of males have no education compared with $58 \%$ of females and $44 \%$ of males in rural areas. Twenty-six percent of the mothers $(16.3 \%$ in urban and $60.3 \%$ in rural) and $20.5 \%$ of the fathers $(11.0 \%$ in urban and $55.7 \%$ in rural) did not attend formal education. Formal education was attended by $83.6 \%$ and $39.6 \%$ of mothers and $89.1 \%$ and $43.7 \%$ of fathers in urban and rural areas respectively. The lack of formal education of mothers in a rural area was four times higher than urban area.

Table 1. Demographic and socioeconomic characteristics of study participants in Bahir Dar city administration, May 2018.

\begin{tabular}{|c|c|c|c|c|c|}
\hline \multirow{2}{*}{ Variables } & & \multicolumn{4}{|c|}{ Residence } \\
\hline & & Urban No (\%) & Rural No (\%) & Total No (\%) & P value \\
\hline \multirow{2}{*}{ Family Head } & male & $411(84.9)$ & $122(93.1)$ & $533(86.7)$ & \multirow{2}{*}{0.140} \\
\hline & female & $73(15.1)$ & $9(6.9)$ & $82(13.3)$ & \\
\hline \multirow{5}{*}{ Marital status } & married & $429(88.6)$ & $121(92.2)$ & $550(89.4)$ & \multirow{5}{*}{.630} \\
\hline & divorced & $29(6.0)$ & $5(3.8)$ & $34(5.5)$ & \\
\hline & widowed & $17(3.5)$ & $2(1.5)$ & $19(3.1)$ & \\
\hline & separated & $4(0.8)$ & $1(0.8)$ & $5(0.8)$ & \\
\hline & single & $5(1.0)$ & $2(1.5)$ & $7(1.1)$ & \\
\hline \multirow{4}{*}{ Religion } & Orthodox & $415(85.7)$ & $120(91.6)$ & $535(87.0)$ & \multirow{4}{*}{.302} \\
\hline & Muslim & $51(10.5)$ & $9(6.9)$ & $60(9.8)$ & \\
\hline & protestant & $14(2.9)$ & $2(1.5)$ & $16(2.6)$ & \\
\hline & other & $4(0.8)$ & $0(0.0)$ & $4(0.7)$ & \\
\hline \multirow{4}{*}{ Ethnic Group } & Amhara & $449(92.8)$ & $131(100.0)$ & $580(94.3)$ & \multirow{4}{*}{$<.01^{*}$} \\
\hline & oromo & $12(2.5)$ & $0(0.0)$ & $12(2.0)$ & \\
\hline & Tigre & $19(3.9)$ & $0(0.0)$ & $19(3.1)$ & \\
\hline & Agawo & $4(0.8)$ & $0(0.0)$ & $4(0.7)$ & \\
\hline \multirow{4}{*}{ Family income } & $<1500$ & $72(14.9)$ & $46(35.1)$ & $118(19.2)$ & \multirow{4}{*}{$<.01^{*}$} \\
\hline & $1501-2999$ & $158(32.6)$ & $81(61.8)$ & $239(38.9)$ & \\
\hline & $3000-4999$ & $143(29.5)$ & $3(2.3)$ & $146(23.7)$ & \\
\hline & $>5000$ & $111(22.9)$ & $1(0.8)$ & $112(18.2)$ & \\
\hline \multirow{2}{*}{ Family size } & $0-4$ & $256(52.9)$ & $39(29.8)$ & $295(48.0)$ & \multirow{2}{*}{$<.01^{*}$} \\
\hline & $>4$ & $228(47.1)$ & $92(70.2)$ & $320(52.0)$ & \\
\hline \multirow{3}{*}{$\begin{array}{l}\text { Number of Under five } \\
\text { children }\end{array}$} & 1 & $22(4.5)$ & $14(10.7)$ & $36(5.9)$ & \multirow{3}{*}{$<.01^{*}$} \\
\hline & 2 & $71(14.7)$ & 44 (33.6) & $115(18.7)$ & \\
\hline & 3 & $391(80.8)$ & $73(55.7)$ & $464(75.4)$ & \\
\hline \multirow{2}{*}{ Decision making of family } & yes & $432(89.3)$ & 87 (66.4) & $519(84.4)$ & \multirow{2}{*}{$<.01^{*}$} \\
\hline & no & $52(10.7)$ & $44(33.6)$ & $96(15.6)$ & \\
\hline \multirow{3}{*}{ Farm-land ownership } & yes & $29(6.0)$ & $103(78.6)$ & $132(21.5)$ & \multirow{3}{*}{$<.01^{*}$} \\
\hline & no & $455(94.0)$ & $27(20.6)$ & $482(78.4)$ & \\
\hline & illiterate & $79(16.3)$ & $79(60.3)$ & $158(25.7)$ & \\
\hline \multirow{3}{*}{ Maternal Education status } & elementary & $169(34.9)$ & $48(36.6)$ & $217(35.3)$ & \multirow{3}{*}{$<.01^{*}$} \\
\hline & high school & $188(38.8)$ & $4(3.1)$ & $192(31.2)$ & \\
\hline & degree & $48(9.9)$ & $0(0.0)$ & $48(7.8)$ & \\
\hline & farmer & $49(10.1 \%$ & $99(75.6)$ & $148(24.1)$ & \\
\hline & GE & $183(37.8 \%$ & $6(4.6)$ & $189(30.7)$ & \\
\hline Occupation of father & merchant & $102(21.1)$ & $6(4.6)$ & $108(17.6)$ & $<.01^{*}$ \\
\hline & POW & $108(22.3)$ & $5(3.8)$ & $113(18.4)$ & \\
\hline & daily labourer & $42(8.7)$ & $15(11.5)$ & $57(9.3)$ & \\
\hline & Housewife & $217(44.8)$ & $79(60.3)$ & $296(48.1)$ & \\
\hline & farmer & $21(4.3)$ & $46(35.1)$ & $67(10.9)$ & \\
\hline Occupation of mother & merchant & $71(14.7)$ & $1(0.8)$ & $72(11.7)$ & $<01^{*}$ \\
\hline Occupation of mother & POW & $38(7.9)$ & $1(0.8)$ & $39(6.3)$ & $<.01$ \\
\hline & GE & $114(23.6)$ & $1(0.8)$ & $115(18.7)$ & \\
\hline & daily labourer & $23(4.8)$ & $3(2.3)$ & $26(4.2)$ & \\
\hline & illiterate & $53(11.0)$ & $73(55.7)$ & $126(20.5)$ & \\
\hline Paternal education & elementary & $117(24.2)$ & $52(39.7)$ & $169(27.5)$ & \\
\hline Paternal education & High school & $166(34.3)$ & $6(4.6)$ & $172(28.0)$ & $<.01$ \\
\hline & degree & $148(30.6)$ & $0(0.0)$ & $148(24.1)$ & \\
\hline
\end{tabular}

POW=private organization worker, GE=Government employee 


\subsection{Child, Maternal Characteristics and Caring Practices}

Of the total children, $314(51.1 \%)$ were males. Their birth order was first birth 279 (45.4), second $250(40.7 \%)$, third 60 (9.8\%) and above forth $26(4.2 \%)$ as indicated in (Table 2$)$. About 190 (30.9\%) of the children were born at home. Home delivery in rural resident mothers was twice higher than in urban mothers. Concerning immunization, $8.9 \%$ of the children did not receive any form of the vaccine and $13.2 \%$ did not receive vitamin A supplementation. From the total study sample, $60(9.8 \%)$ had diarrhea in the two weeks preceding the study; urban $9.5 \%$ and rural $10.7 \%$. About $91 \%$ of the preschool children have initiated breastfeeding within the hour after delivery and fed colostrum. However, only $15.0 \%$ of mothers have given the child pre-lacteal food/fluid immediately after delivery.

Eighty-nine percent of women who gave birth in the three to five years preceding the survey were received antenatal care visits from health facilities at 3 months of pregnancy. Antenatal care visit to a health facility was common among women in urban $455(94.0 \%)$ than rural 94 (71.8\%). Mothers who gave first birth at age 18 or fewer years were 132 $(21.5 \%)$ which were $73(55.7 \%)$ from rural and $59(12.2 \%)$ from urban. Ninety-seven percent of mothers have born 1 to 4 children and $3 \%$ have born more than four children per head.

Table 2. Child, maternal characteristics and caring practices in Bahir Dar city administration, May 2018.

\begin{tabular}{|c|c|c|c|c|c|}
\hline \multirow{2}{*}{ Variables } & & \multicolumn{4}{|l|}{ Residence } \\
\hline & & urban No \% & rural No \% & Total No \% & P Value \\
\hline \multirow{2}{*}{ Child sex } & male & $250(51.7)$ & $64(48.9)$ & $314(51.1)$ & \multirow{2}{*}{.570} \\
\hline & female & $234(48.3)$ & $67(51.1)$ & $301(48.9)$ & \\
\hline \multirow{4}{*}{ Birth order } & 1 & $235(48.6)$ & $44(33.6)$ & $279(45.4)$ & \multirow{4}{*}{$<.01^{*}$} \\
\hline & 2 & $200(41.3)$ & $50(38.2)$ & $250(40.7)$ & \\
\hline & 3 & $38(7.9)$ & $22(16.8)$ & $60(9.8)$ & \\
\hline & others & $11(2.3)$ & $15(11.5)$ & $26(4.2)$ & \\
\hline \multirow{2}{*}{ Place of delivery } & $\mathrm{HF}$ & $371(76.7)$ & $54(41.2)$ & $425(69.1)$ & \multirow{2}{*}{$<.01^{*}$} \\
\hline & home & $113(23.3)$ & $77(58.8)$ & $190(30.9)$ & \\
\hline \multirow{2}{*}{ Diarrhoea } & yes & $46(9.5)$ & $14(10.7)$ & $60(9.8)$ & \multirow{2}{*}{.686} \\
\hline & no & $438(90.5)$ & $117(89.3)$ & $555(90.2)$ & \\
\hline \multirow{2}{*}{ Exclusive Breastfeeding } & $=<4$ & $25(5.2)$ & $3(2.3)$ & $28(4.6)$ & \multirow{2}{*}{.161} \\
\hline & $>4$ & $459(94.8)$ & $128(97.7)$ & $587(95.4)$ & \\
\hline \multirow{3}{*}{ Duration of breastfeeding } & $<18$ & $77(15.9)$ & $20(15.3)$ & $97(15.8)$ & \multirow{3}{*}{.984} \\
\hline & $18-23$ & $26(5.4)$ & $7(5.3)$ & $33(5.4)$ & \\
\hline & $>23$ & $381(78.7)$ & $104(79.4)$ & 485 (78.9) & \\
\hline \multirow{2}{*}{ Colostrums' feeding } & yes & $463(95.7)$ & $98(74.8)$ & $561(91.2)$ & \multirow{2}{*}{$<.01^{*}$} \\
\hline & no & $21(4.3)$ & $33(25.2)$ & $54(8.8)$ & \\
\hline \multirow{2}{*}{ Vitamin A supplementation } & yes & $434(89.7)$ & $100(76.3)$ & $534(86.8)$ & \multirow{2}{*}{$<.01^{*}$} \\
\hline & no & $50(10.3)$ & $31(23.7)$ & $81(13.2)$ & \\
\hline \multirow{2}{*}{ Prelacteal feeding } & yes & $45(9.3)$ & $47(35.9)$ & $92(15.0)$ & \multirow{2}{*}{$<.01^{*}$} \\
\hline & no & 439 (90.7) & $84(64.1)$ & $523(85.0)$ & \\
\hline \multirow{2}{*}{ Vaccination } & yes & $455(94.0)$ & $105(80.2)$ & $560(91.1)$ & \multirow{2}{*}{$<.01^{*}$} \\
\hline & no & $29(6.0)$ & $26(19.8)$ & $55(8.9)$ & \\
\hline Antenatal care visit & yes & $455(94.0)$ & $94(71.8)$ & $549(89.3)$ & $<.01^{*}$ \\
\hline \multirow{2}{*}{ Total number of children } & $0-4$ & $475(98.1)$ & $124(94.7)$ & $599(97.4)$ & \multirow{2}{*}{$.026^{*}$} \\
\hline & $>4$ & $9(1.9)$ & $7(5.3)$ & $16(2.6)$ & \\
\hline \multirow{4}{*}{ Mother age at first birth } & $14-19$ & $59(12.2)$ & $73(55.7)$ & $132(21.5)$ & \multirow{4}{*}{$<.01^{*}$} \\
\hline & $20-24$ & $260(53.7)$ & $58(44.3)$ & $318(51.7)$ & \\
\hline & $25-29$ & $156(32.2)$ & $0(0.0)$ & $156(25.4)$ & \\
\hline & $30-34$ & $9(1.9)$ & $0(0.0)$ & $9(1.5)$ & \\
\hline
\end{tabular}

\subsection{Environmental and Health Condition}

More than three-quarters $(76.7 \%)$ of the households in the study area have access to an improved source of drinking water, with a higher proportion among urban households (93\%) than among rural households (16\%). The most common source of improved drinking water in urban households was piped water, used by $93 \%$ of urban and $16 \%$ of rural households. Fifty-six percent of rural households have access to drinking water from a protected well and river while $26 \%$ used a protected pond. Rural houses were more likely to have dung floors or sand floor $(91.6 \%)$, while urban houses made from vinyl/ceramic asphalt strips $(8.5 \%)$, or with cement floors $(53.1 \%)$.

Only half $(50.9 \%)$ of the households in the district used improved toilet facilities that were not shared with other households and made from cement. Forty-nine percent of households were used non-improved toilet facilities (93\% in rural and $36 \%$ in urban) areas. The most common type of non-improved toilet facility was an open pit latrine or pit latrine without slabs, used both by households in rural and urban areas (Table 3). 
Table 3. Environmental conditions in Bahir Dar city administration, May 2018.

\begin{tabular}{|c|c|c|c|c|c|}
\hline \multirow{2}{*}{ Variables } & & \multicolumn{4}{|l|}{ Residence } \\
\hline & & Urban No (\%) & Rural No (\%) & Total No (\%) & $P$ value \\
\hline \multirow{4}{*}{ Source of water } & well & $5(1.0)$ & $12(9.2)$ & $17(2.8)$ & \multirow{4}{*}{$<.01^{*}$} \\
\hline & river & $21(4.3)$ & $62(47.3)$ & $83(13.5)$ & \\
\hline & spring & $8(1.7)$ & $35(26.7)$ & $43(7.0)$ & \\
\hline & tap water & $450(93.0)$ & $22(16.8)$ & $472(76.7)$ & \\
\hline \multirow{2}{*}{ Type of house } & thukul/thatched & $288(59.5)$ & $126(96.2)$ & $414(67.3)$ & \multirow{2}{*}{$<.01^{*}$} \\
\hline & cement & $196(40.5)$ & $5(3.8)$ & $201(32.7)$ & \\
\hline \multirow{3}{*}{ Type of floor } & earth & $186(38.4)$ & $120(91.6)$ & $306(49.8)$ & \multirow{3}{*}{$<.01^{*}$} \\
\hline & cement & $257(53.1)$ & $11(8.4)$ & $268(43.6)$ & \\
\hline & ceramic & $41(8.5)$ & $0(0.0)$ & $41(6.7)$ & \\
\hline \multirow{3}{*}{ Type of latrine } & wooden & $178(36.8)$ & $122(93.1)$ & $300(48.8)$ & \multirow{3}{*}{$<.01^{*}$} \\
\hline & cement & $304(62.8)$ & $9(6.9)$ & $313(50.9)$ & \\
\hline & other & $2(0.4)$ & $0(0.0)$ & $2(0.3)$ & \\
\hline
\end{tabular}

\subsection{Nutritional Status of the Children}

The overall prevalence of stunting was 30.9\% (urban; $27.7 \%$, rural; $42.7 \%$ ), wasting $7 \%$ (urban; $6.4 \%$, rural; 9.2\%) and underweight $18.7 \%$ (urban; $14.7 \%$, rural; $33.6 \%$ ) respectively. In addition, the prevalence of severe stunting; underweight and wasting were $16.7 \%, 5.9 \%$, and $3.4 \%$ respectively. The details on the nutritional status of preschool children in Bahir Dar city administration is presented both in Table 4 and Figure 3.

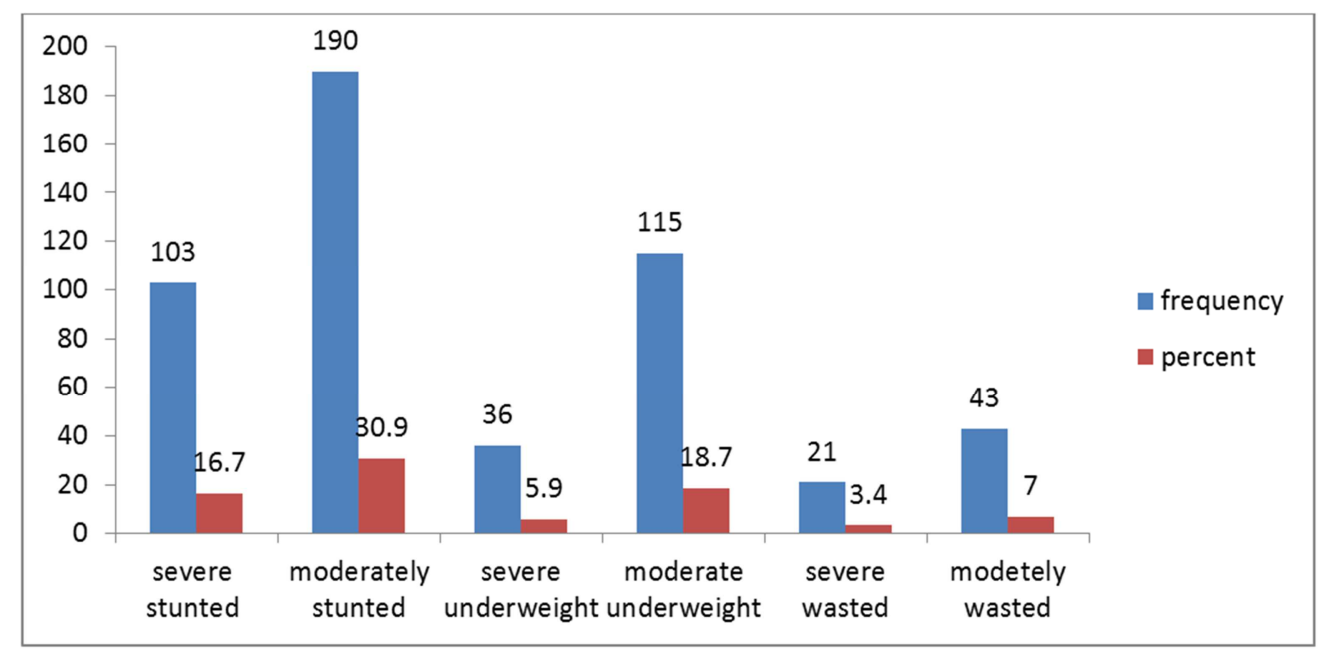

Figure 3. Nutritional status of preschool children in Bahir Dar city administration, May 2018.

The prevalence of stunting was decreased as mothers secure a job, with the highest prevalence of chronic malnutrition found in jobless mothers (52.6\%) and lowest in mothers working in private organizations (4.2\%). The mothers' levels of education have an inverse relationship with stunting levels. Children of mothers with more than secondary education were the least likely to be stunted $(8.4 \%)$, while children of uneducated mothers were the most likely to be stunted (35.8\%). A similar inverse relationship was observed between household wealth and stunting levels of children.

Wasting was higher in rural (9.2\%) than in urban children $(6.4 \%)$. The male family headed children were more likely to be wasted $(90.7 \%)$ than female-headed children $(9.7 \%)$. Wasting was higher in children who have not taken vitamin A supplementation (88.4\%) than those who had (11.6\%).

The proportion of underweight in children varies by residence. Rural children were more likely to be underweight (33\%) than urban children (14.7\%). The ratio of underweight children was nearly above three times higher for those born from uneducated mothers relative to secondary education $(44.3 \%$ versus $13.9 \%)$. The percentage of underweight children was decreased as household wealth increased. Children born in the lowest wealth quintile were more than twice underweight than children born in the highest wealth quintile ( $27 \%$ compared with $13.9 \%$ ).

Table 4. Nutritional status of preschool children in Bahir Dar district, May 2018.

\begin{tabular}{lllll}
\hline & & Residence & & \\
\cline { 3 - 5 } & & Urban No (\%) & Rural No (\%) & Total No (\%) \\
\hline \multirow{3}{*}{ stunting } & severe & $70(14.5)$ & $33(25.2)$ & $103(16.7)$ \\
& moderate & $134(27.7)$ & $56(42.7)$ & $190(30.9)$ \\
\hline
\end{tabular}




\begin{tabular}{lllll}
\hline \multirow{2}{*}{} & & Residence & & Total No (\%) \\
\cline { 3 - 5 } underweight & Urban No (\%) & Rural No (\%) & $36(5.9)$ \\
& severe & $22(4.5)$ & $14(10.7)$ & $115(18.7)$ \\
\multirow{3}{*}{ wasting } & moderate & $71(14.7)$ & $44(33.6)$ & $464(75.4)$ \\
& normal & $391(80.8)$ & $53(55.7)$ & $21(3.4)$ \\
& severe & $16(3.3)$ & $12(9.8)$ & $43(7.0)$ \\
\hline
\end{tabular}

\subsection{Factors Associated with Underweight}

Family income [AOR=.233 at 95\% CI (.085-.637)], number of under-five [AOR=2.618 at 95\% CI (1.751-9.124)], source of water $[\mathrm{AOR}=2.852$ at $95 \% \mathrm{CI}(1.029-7.901)]$, paternal education $[\mathrm{AOR}=4.19$ at $95 \% \mathrm{CI}(1.298-13.527)]$, maternal education [AOR $=2.740$ at $95 \% \mathrm{CI}(1.193-6.294)]$, and family head $[\mathrm{AOR}=.421$ at $95 \% \mathrm{CI}(.233-.762)]$, were significantly associated with underweight during bivariate and multivariate logistic regression analysis (Table 5).

Table 5. Bivariate and multiple logistic regression analysis of selected correlates of underweight, Bahir Dar city administration, May 2018.

\begin{tabular}{|c|c|c|c|c|}
\hline variables & & No (\%) & COR & AOR \\
\hline \multirow{4}{*}{ Family income } & $<1500$ & $31(27.0)$ & $2.153(1.097-4.223) *$ & $.371(.109-1.261)$ \\
\hline & $1501-2999$ & $58(50.4)$ & $2.014(1.094-3.708)$ & $.465(.157-1.375)$ \\
\hline & $3000-4999$ & $10(8.7)$ & $.429(.186-.989) *$ & $.233(.085-.637) *$ \\
\hline & $>5000$ & $16(13.9)$ & 1 & 1 \\
\hline \multirow{5}{*}{ Occupation of father } & farmer & $47(40.9)$ & $1.039(1.535-2.017)$ * & $.241(1.091-.638)$ \\
\hline & GE & $24(20.9)$ & $.318(.157-.646)$ & $1.213(.420-3.506)$ \\
\hline & merchant & $17(14.8)$ & $.406(.189-.875)$ & $.791(.278-2.248)$ \\
\hline & POW & $9(7.8)$ & $.199(.082-.483)$ & $.449(.148-1.363)$ \\
\hline & daily laborer & $18(15.7)$ & 1 & 1 \\
\hline \multirow{2}{*}{ Residence } & urban & $71(61.7)$ & $.301(.192-.473) *$ & $2.155(.897-5.178)$ \\
\hline & rural & $44(38.3)$ & 1 & 1 \\
\hline \multirow{3}{*}{$<$ five children } & 1 & $46(40.0)$ & $2.124(1.499-3.011)$ & $1.485(.406-5.428)$ \\
\hline & 2 & $64(55.7)$ & $2.124(1.499-3.011) *$ & $2.618(1.751-9.124)$ * \\
\hline & 3 & $5(4.3)$ & 1 & 1 \\
\hline \multirow{2}{*}{ Type of house } & thukul/thatched & $94(81.7)$ & $2.588(1.555-4.308)^{*}$ & $1.269(.526-3.061)$ \\
\hline & cement & $21(18.3)$ & 1 & 1 \\
\hline \multirow{4}{*}{ source of water } & well & $5(4.3)$ & $3.331(1.100-10.08)$ * & $2.377(1.565-9.995)$ * \\
\hline & river & $29(25.2)$ & $4.599(2.662-7.945)$ & $2.852(1.029-7.901)$ * \\
\hline & pond & $22(19.1)$ & $7.713(3.939-15.104)$ & $4.834(1.521-15.367)$ \\
\hline & tap water & $59(51.3)$ & 1 & 1 \\
\hline \multirow{3}{*}{ Type of floor } & earth & $80(69.6)$ & $3.645(1.258-0.59)$ & $1.523(.373-6.223)$ \\
\hline & cement & $31(27.0)$ & $1.280(.427-3.837)$ & $1.130(.337-3.788)$ \\
\hline & ceramic & $4(3.5)$ & 1 & 1 \\
\hline \multirow{2}{*}{ Ownership of animals } & yes & $54(47.0)$ & $2.883(.886-4.408)$ & $.725(.311-1.69)$ \\
\hline & no & $61(53.0)$ & 1 & 1 \\
\hline \multirow{3}{*}{ Bathing frequency } & daily & $20(17.4)$ & $.740(.412-1.331)$ & $.844(.436-1.633)$ \\
\hline & twice weekly & $57(49.6)$ & $1.731(1.089-2.750)$ & $.988(.551-1.772)$ \\
\hline & weekly & $38(.0)$ & 1 & 1 \\
\hline \multirow{4}{*}{ Mother age at first birth } & $14-19$ & $46(40.0)$ & $2.118(.422-10.636)$ & $.929(.140-6.179)$ \\
\hline & $20-24$ & $49(42.6)$ & $.686(.138-3.401)$ & $.481(.093-2.496)$ \\
\hline & $25-29$ & $18(15.7)$ & $2.118(.422-10.636)$ & $.638(.104-3.903)$ \\
\hline & $30-34$ & $2(1.7)$ & 1 & 1 \\
\hline \multirow{4}{*}{ Paternal education } & illiterate & $51(44.3)$ & $6.03(3.19-11.402) *$ & $4.19(1.298-13.527) *$ \\
\hline & elementary & $32(27.8)$ & $2.049(1.070-3.925)$ & $1.892(.640-5.593)$ \\
\hline & high school & $16(13.9)$ & $.828(.398-1.722)$ & $1.098(.428-2.817)$ \\
\hline & degree and above & $16(13.9)$ & 1 & 1 \\
\hline \multirow{2}{*}{ Residence } & urban & $71(61.7)$ & $.301(.192-.473) *$ & $2.155(.897-5.178)$ \\
\hline & rural & $44(38.3)$ & 1 & 1 \\
\hline \multirow{2}{*}{ ANC visit } & yes & $94(81.7)$ & $.422(.238-.749) *$ & $1.232(.466-3.252)$ \\
\hline & no & $21(18.3)$ & 1 & 1 \\
\hline \multirow{2}{*}{ Prelacteal feeding } & yes & $97(84.3)$ & $2.045(1.220-3.427)$ * & $.815(.360-1.845)$ \\
\hline & no & $18(15.7)$ & 1 & 1 \\
\hline \multirow{2}{*}{ Place of delivery } & health facility & $64(55.7)$ & $.463(.304-.705)$ & $.738(.391-1.392)$ \\
\hline & home & $51(44.3)$ & 1 & 1 \\
\hline \multirow{2}{*}{ Child sex } & Female & $285(49.2)$ & $.664(.440-1.002)$ & $.663(.430-1.024)$ \\
\hline & Male & $294(50.8)$ & 1 & 1 \\
\hline
\end{tabular}




\begin{tabular}{lllll}
\hline variables & & No (\%) & COR & AOR \\
\hline \multirow{3}{*}{ Maternal education } & Illiterate & $149(25.7)$ & $2.047(.939-4.462)$ & $2.740(1.193-6.294) *$ \\
& elementary & $208(35.9)$ & $.688(.311-1.520)$ & $.863(.376-1.978)$ \\
& High school & $178(30.7)$ & $.290(.119-.708) *$ & $.346(.138-.866) *$ \\
\multirow{2}{*}{ Family head } & degree and above & $44(7.6)$ & 1 & 1 \\
& Female & $77(13.3)$ & $.527(.308-.902)$ & $.421(.233-.762) *$ \\
& Male & $502(86.7)$ & 1 & 1 \\
\hline
\end{tabular}

$\mathrm{POW}=$ private organization worker, $\mathrm{GE}=$ Government employee

\subsection{Factors Associated with Stunting}

Occupation of father $[\mathrm{AOR}=2.015$ at $95 \% \mathrm{CI}(1.89-4.959)]$, duration of breast feeding $[\mathrm{AOR}=.500$ at $95 \% \mathrm{CI}(.270-.927)]$, ownership of domestic animals $[\mathrm{AOR}=.427$ at $95 \% \mathrm{CI}(.193-.946)]$, were significantly associated with stunting in multivariate logistic regression analysis (Table 6).

Table 6. Bivariate and multiple logistic regression analysis of selected correlates of stunting, Bahir Dar city administration, May 2018.

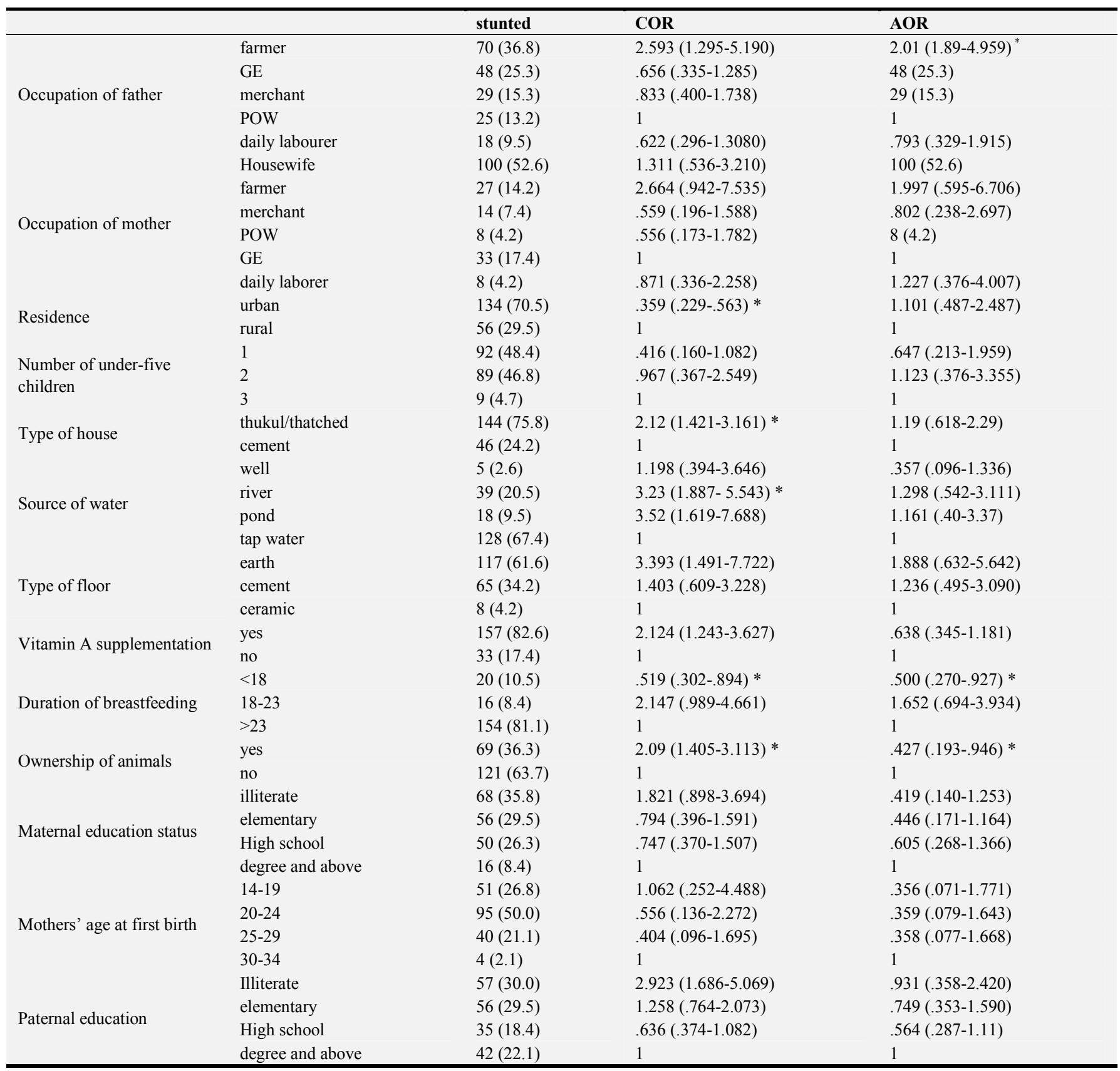

POW=private organization worker, GE=Government employee 


\subsection{Factors Associated with Wasting}

Only duration of breastfeeding has a significant association with wasting in multivariate logistic regression at $[\mathrm{AOR}=2.28$ at 95\% CI (1.870-5.992)] (Table 7).

Table 1. Bivariate and multiple logistic regression analysis of selected correlates of wasting, Bahir Dar city administration, May 2018.

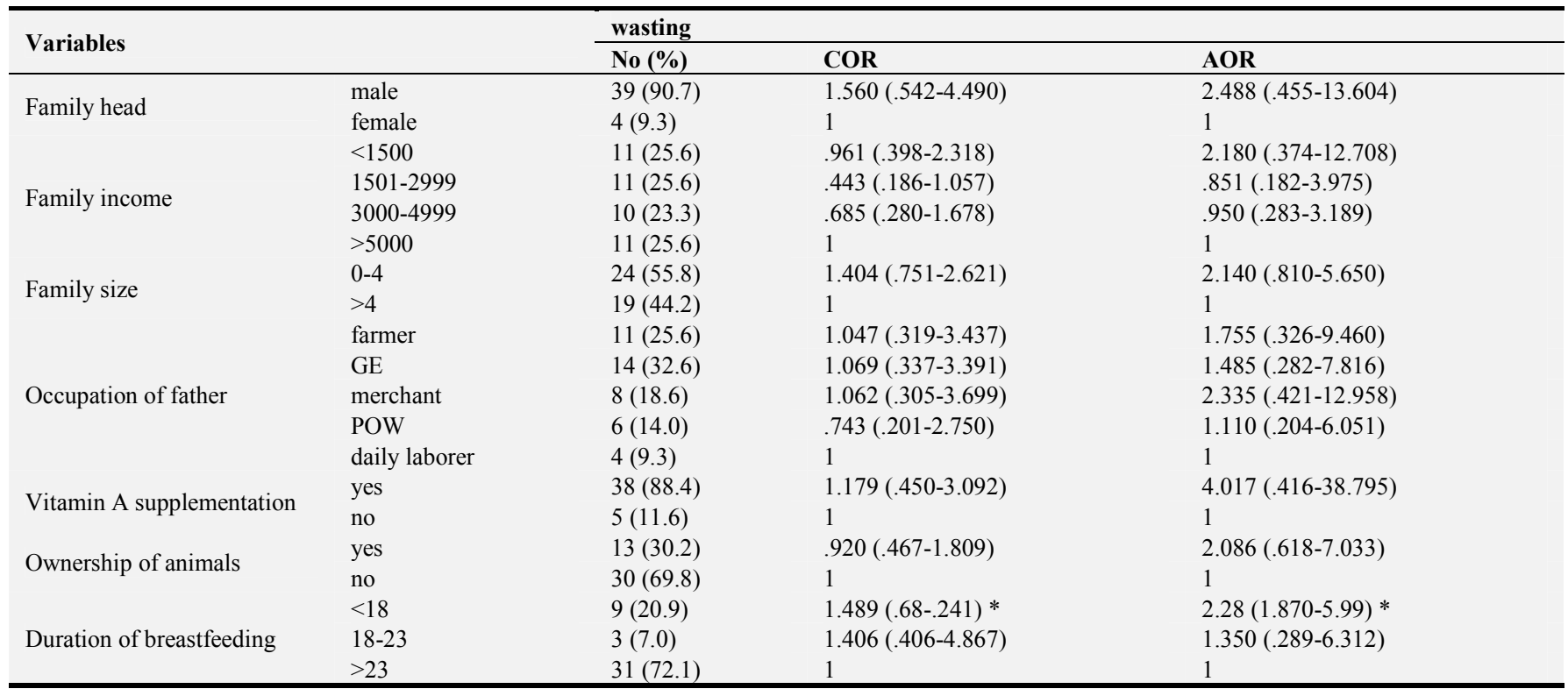

$\mathrm{POW}=$ private organization worker, $\mathrm{GE}=$ Government employee.

\section{Discussion}

The study indicated that the prevalence of stunting, underweight and wasting were $40 \%, 25 \%$ and $9.0 \%$ respectively which were lower than the Mini EDHS 2014 report of stunting, underweight and wasting 30.9\%, 18.7\% and $7.9 \%$ respectively [7]. In addition to this, wasting $7.0 \%$ and severe wasting $3.4 \%$ in the study area were also lower than that of the national $(9.0 \%$ wasting and $3.0 \%$ severe wasting) as well as Amhara regional state (9.7\% wasting and $2.3 \%$ severe wasting) DHS report [4].

The prevalence of stunting and wasting were lower as compared to the finding of community cross-sectional study in rural kebeles of Bule Hora district, in which $42.2 \%$ stunted and $14.1 \%$ wasted [8]. However, the stunting level was similar to the finding in Gimbi district 32.4\% [9], which showed that the extent of stunting among towns had no difference. Malnutrition was an existent problem in Bahir Dar district as measured through three indicators (underweight, stunting, and wasting). This can also warrant through observing rural community members, that there were inadequate child caring practices mainly on child feeding and hygiene.

The prevalence of underweight was lower as compared to both the national nutrition program of the country and west Gojam zone which were $27.0 \%$ and $49.2 \%$ respectively [4, 10]. This difference might be happened due to socioeconomic class, sample size, study district, the extent of the study, and setting of the study. The children breastfed for more than 24 months was less likely at risk of stunting compared to children breastfed for less than 18 months. This finding was similar to [9], in which children breastfeed for 12-24 months were seven times more likely at risk of malnutrition when compared to children breastfed more than 24 months.

Regarding associated factors of wasting, the study revealed duration of breastfeeding was found to be significantly related to wasting. A child breastfed less than 18 months was two times wasted than who fed for more than 24 months. Breast milk consists of well enriched nutrients which provide a child to be healthy and strong. It also supports the growth of immunity that prevents opportunistic infections which cause susceptible to diseases like diarrhea. These nutrients are recognized to halt disease spread by improving children's immunity and breaking of the infection-malnutrition cycle. Furthermore, it might perk up child survival, growth, maturity and prevents the outcome of under nutrition in later life $[11,12]$.

Family income was significantly associated with underweight. Children whose family monthly income greater than 5000 Birr were less likely affected by underweight as compared to family income less than 1500 birr. The finding was in agreement with $[13,14]$. Children belonging to the lower-income group were at a higher threat of being underweight than children of higher income families. Lowincome levels of household limit the kinds and amounts of food available for consumption. Lower income also raises the likelihood of infection through poor personal and environmental hygiene [14]. Income growth at the household and national levels imply parallel rates of decline in malnutrition [13]. 
The sex of the household head was significantly associated with child malnutrition signifying that being female-headed was positively correlated with underweight and stunting of children. This might happen due to various socio-cultural norms and morals, that women have limited liberty of mobility and involvement in different meetings and as a result, have limited access to information and possessions [15]. Thus, the children of female-headed households were underweight relative to male-headed ones. The higher percentage of underweight in pre-school children of the female-headed household might be due to lack of support structures and vulnerability in accessing services, including food as a result of cultural discrimination and limited mobility [16, 17].

Lower risk of malnutrition was anticipated with children of learned parents. According to Christiaensen and Alderman [18] women schooling, in particular, was one of the key elements to improve child nutrition. In addition, education enhances the potential of individuals to access and use information from various sources. The children of educated families were four times less likely to be underweight than those of illiterate ones. Other investigations also support family education improved child nutrition through the management of scarce resources, follow-up of health services and healthy lifestyle $[16,18]$. Moreover, a nationwide study indicated that improved women education decreases the occurrence of child malnutrition approximately five to ten percent. The problem-solving ability of mothers in combination with their maternal autonomy would reduce child stunting and underweight by ten to twenty percent [4]. The results of this paper corroborate with the high prevalence of stunting found in children of illiterate mothers than children of educated ones [3, 10, 15, 19]. The findings of the authors were also supported by the study that affirmed the significance of women's status for child nutrition in SubSaharan Africa, South Asia, and Latin America [17] Similar to the finding of Hidabu Abote district [6], this work also revealed having more under-five children in households had a positive relationship with underweight. Children from the family who had two children were about 2.6 times more distressed by underweight in comparison to the family who had one child.

The utilization of protected water supply in the households decreased the threat of underweight more than three-fold compared to exposed (open source) water. In the countryside, there was insufficient access to protected water. This exasperated poor sanitary habits which were the main causes for the spread of diseases. The national study also indicated a big gap in the supply and coverage of protected drinking water of the country $(30 \%)$, urban $(84 \%)$, and rural $(21 \%)$ areas [4]. Besides, analysis of EDHS 2011 data revealed significant externalities related to access to safe water and sanitation [20].

Generally, urban children have a better nutritional status than their rural counterparts particularly for linear growth (stunting) and underweight. It was also suggested that awareness and availability of the variety of foods in urban areas made a good opportunity regarding the decreasing rate of urban malnutrition. This study supports a government to take an action towards the gaps. It will also use as a baseline study for further invsetigations.

\section{Conclusion and Recommendation}

\subsection{Conclusion}

The high prevalence of stunting in the area was a big concern both in rural and urban areas. However, rural resident children were more exposed to nutritional risk factors than their urban counterparts. Ownership of domestic animals, duration of breastfeeding, and occupation of the father were significant factors of stunting while the family head, number of under-five children, residence, source of water, maternal education, and paternal education were the main factors for underweight. However, the duration of breastfeeding was the only factor for wasting.

\subsection{Recommendation}

Nutritional education should be strengthened through multi-sectoral interventions to improve the knowledge and feeding practice of parents on child feeding. Further research is also required to investigate child-caring practices and dietary assessments.

\subsection{Strength and Weakness of the Study}

\subsubsection{Strength}

Many variables were considered to be factors of child malnutrition and standardized questionnaire used in other studies were adapted to this study.

\subsubsection{Weakness}

The cross-sectional nature of this data did not allow us to examine causality in the relationship between malnutrition and diverse risk factors. In addition to this, seasonality should be given special attention; the season of the year might have a significant effect both on food security and nutritional status. Therefore, consecutive measurements were desirable. In addition to this, certain measurements might not be accurate and precise due to subjective responses and recall biases from answers based on the reminiscence of the mothers and possible dilution effect of selecting one child from a household.

\section{Abbreviations and Acronyms}

ANC: Anti Natal Care, AOR: Adjusted Odds Ratio, CI: Confidence Interval, COR: Crude Odds Ratio, SD: Standard deviation, EDHS: Ethiopian Demographic and Health Survey, HH: House Hold, MAM: Moderate Acute Malnutrition, MUAC: Mid-Upper Arm Circumference, NCHS: National Center for Health Statistics, PEM: Protein-Energy Malnutrition, SPSS: Statistical Package for Social Science, UNICEF: United Nations Intentional Children fund, WHO: World Health Organization 


\section{Declarations}

Ethics Approval and Consent to Participate

Ethical clearance was obtained from the ethical clearance committee of the Faculty of Chemical and Food Engineering, Bahir Dar University (Ref.no./BiT/SCFE/259/2017) and permission to conduct the study was obtained from Amhara Regional Health Research Bureau. Informed consent was also obtained verbally from all the study participants after explaining the study objectives, because they were unable to read and write. Participation was voluntary and mothers were interviewed based on their interest and children also measured.

\section{Availability of Data and Materials}

The datasets used and/or analyzed during the current study can be obtained from the corresponding author on reasonable request.

\section{Competing Interests}

The author declares that there will be no competing interests.

\section{Funding}

This study was sponsored by Bahir Dar Institute of Technology to BRJ for the completion of his Master of Science in Applied Human Nutrition.

\section{Author's Contribution}

BRJ designed the study, participated in data collection, analyzed and interpreted the data.

\section{Acknowledgements}

The author wishes to acknowledge Bahir Dar University, Institute of Technology for funding this research. I would also like to thank the data collectors and study participants who devoted their time to participate in this study.

\section{References}

[1] Redi F. Prevalence of Malnutrition among Children Aged 659 in Haramaya. Journal of Biometrics \& Biostatistics. 2017; $6-10$.

[2] UNICEF. Tracking Progress on Child and Maternal Nutrition; A survival and development priority [Internet]. New York, NY 10017, USA; 2009. 124. Available from: www.unicef.org/publications.

[3] Smith LC, Haddad L. Overcoming Child Malnutrition in Developing Countries - Past Achievements and Future Choices. 2020 Vision for Food, Agriculture, and the Environment. Discussion Paper 30 (IFPRI, 2000, 73 p.): International Food Policy Research Institute. 2000; (30): 73.
[4] Central Statistical Agency Ethiopia and ORC Macro. Ethiopia. Ethiopia Demographic and Health Survey 2011 Addis Ababa, Ethiopia and Calverton, Maryland, USA: Central Statistical Agency and ICF International. 2011; 452.

[5] Temesgen M. Status of Ethiopian Weaning and Complementary Foods: A Review. Open Access Scientific Reports. 2013; 2 (2): 10.

[6] Mengistu K, Alemu K, Destaw B. Prevalence of Malnutrition and Associated Factors Among Children Aged 6-59 Months at Hidabu Abote District, North Shewa, Oromia Regional State. Nutritional Disorders \& Therapy. 2013.

[7] Central Statistics Agency [Ethiopia]. Mini DHS. Ethiopia Mini Demographic and Health Survey. 2014; (July): 1-111.

[8] Asfaw M, Wondaferash M, Taha M, Dube L. Prevalence of undernutrition and associated factors among children aged between six to fifty-nine months in Bule Hora district, South Ethiopia. BMC Public Health. 2015; 15 (41): 1-9.

[9] Eticha Kebede. Prevalence and Determinants of Child Malnutrition Western Ethiopia, Gimbi District, Oromia Regional State; 2009.

[10] Teshome B, Kogi-makau W, Getahun Z, Taye G. Magnitude and determinants of stunting in children under- five years of age in food surplus region of Ethiopia: The case of West Gojam Zone. Ethiop J Health Dev. 2009; 23 (2): 10.

[11] WHO. Learning from large-scale community-based programmes to improve breastfeeding practices. Geneva; 2008.

[12] Al-Sahab B, Lanes A, Feldman M, Tamim H. Prevalence and predictors of 6-month exclusive breastfeeding among Canadian women: A national survey. BMC Pediatrics. 2010 Apr 8; 10.

[13] Haddad L. Reducing Child Malnutrition: How Far Does Income Growth Take Us? The World Bank Economic Review [Internet]. Available from: https://academic.oup.com/wber/articlelookup/doi/10.1093/wbe r/lhg012.

[14] Gillespie S, Haddad L, Mannar V, Menon P, Nisbett N. The politics of reducing malnutrition: Building commitment and accelerating progress. The Lancet. 2013; 382 (9891): 552-69.

[15] Carolina N, Hill C, Street F. Maternal autonomy is inversely related to child stunting in Andhra Pradesh, India. NIH Public Access. 2013; 5 (1): 5.

[16] Herrador Z, Sordo L, Gadisa E, Moreno J, Nieto J, Benito A, et al. Cross-sectional study of malnutrition and associated factors among school aged children in rural and urban settings of fogera and libo kemkem districts, Ethiopia. PLoS ONE. 2014; 9 (9): 1-11.

[17] Smith LC, Ramakrishnan U, Ndiaye A, Haddad L, Martorell R. The Importance of Women's Status for Child Nutrition in Developing Countries. 2003.

[18] Christiansen LJ, Alderman H. Child Malnutrition in Ethiopia: Can Maternal Knowledge Augment the Role of Income? 2001; (22). Available from: http://www.worldbank.org/afr/wps/index.html.

[19] Edris M. Assessment of nutritional status of preschool children of preschool children of Gumbrit. Ethiopia J Health Dev. 2006; 21: 125-9. 
[20] Liaqat P, Rizvi MA, Qayyum A, Ahmed H. Association between complementary feeding practice and mother's education status in Islamabad. Journal of Human Nutrition and Dietetics. 2007 Aug; 20 (4): 340-4. 